\title{
Association between Periodontitis and Respiratory Disease-A review.
}

\author{
${ }^{1}$ Daveinthiran Thanabalan, ${ }^{2}$ Dr. Sheeja \\ Association Between Periodontitis and Respiratory Disease-A review
}

\begin{abstract}
The oral cavity has been considered as a site of colonization of respiratory pathogens.The colonization of respiratory pathogens appears to be a risk factor for lung infection in high risk subjects. The mechanism of lung infection could be due to aspiration of the pathogens into the lungs. Edentulous patient are less likely to be affected compare to dentulous patient or patient who are using dentures.Most common pulmonary disease associated with periodontitis are Chronic obstructive pulmonary disease and pneumonia.These review underline the importance of improving oral hygiene among patients who are at risk.
\end{abstract}

\section{Introduction:}

Over the past decade,intense studies had been carried out to understand the relationship between periodontitis and respiratory disease.This is due to the anatomical continuity between lungs and oral cavity,thus making the oral cavity as a site of colonization of respiratory pathogens.1.Furthermore ,the recent increase of tobacco usage had increase the severity of periodontal disease and chronic respiratory disease.

An infection in the lungs usually occurs when the microorganism enters the lungs via inhalation or aspiration,which is the commonest route.1.The respiratory pathogen is mixed into salivary secretion along with the oral bacteria and pro inflammatory cells. This cause the contamination of the lungs, thus inducing changes upon respiratory epithelium.2,3.Upon aspiration the upper airway environment is altered, thus leading to colonization of respiratory pathogen in lower respiratory tract.3.Colonization of bacteria occurs due to destruction of macromolecules on mucosal surface to expose receptors and lead to colonization.4.

Therefore, there are high chances of periodontal disease lading to exacerbation of respiratory disease especially when the host defence is compromised.

\section{Periodontitis}

Periodontitis is a set of inflammatory disease affecting the periodontium.Periodontits usually leads to alveolar bone loss around the teeth which will lead to loosening of teeth if left untreated. It occurs when the microorganism adhere and grow on tooth surface along with aggressive immune response against microorganism.5.Age, diabetic , and smoking increase the prevalence of periodontitis.6.

\section{Oral Mucosa:A Site of Colonization of Periodontal Pathogen.}

Recent studies have proven that the oral cavity is a sit of colonization of respiratory pathogen.Lack of attention to oral hygiene result in increased mass and complexity of dental plaque which may lead to bacterial interaction indigenous plaque bacteria and respiratory pathogen.7.This result in colonization of dental plaque by respiratory pathogen.This plaque may shed into saliva and contaminate the distal portion of respiratory tree upon aspiration.Futhermore ,the respiratory pathogen in dental plaque is difficult to eradicate. This respiratory pathogen are more likely to colonize in oral cavities of patient with teeth or denture rather than edentulous patient .8.This can be concluded that respiratory pathogen colonization is favoured by non shedding surface or conditioning of mucosal surface by dental plaque.

\section{Pulmonary Disease}

The pulmonary disease often associated with periodontits are:-

i)Pneumonia

ii)Chronic obstructive pulmonary disease

\section{Pneumonia}

Pneumonia is defined as inflammation of lungs caused by fungal,viral,parasites,and bacterial infection.9.Pneumonia is classified into Community acquired Pneumonia (CAP) and hospital acquired pneumonia(HAP).A subset of hospital acquired pneumonia known as ventilator associated Pneumonia(VAP) which occurs on placement of endotracheal tube which may transport oropharyngeal organism into lower airway.9.Bacterial pneumonia is initiated via colonization of respiratory pathogen in oral mucosa and pharyngeal mucosa which leads to aspiration in to lower airway.Condition which induce excessive aspiration of 
oral secretion is stroke,Parkinson Disease ,alcohol abuse.Furthermore,impaired defence mechanism as seen in malnutrition ,smoking,COPD prevent the elimination of aspirated bacteria from lower airway.CAP is usually caused by aspiration of streptococcus pneumoniae,Hemophilusinfluenze, and mycoplasma pneumonia.These bacteria usually reside in the oropharynx.9.

\section{Copd}

Chronic obstructive pulmonary disease Is a lung disease characterized by poor airflow as a breakdown of lung tissue(emphysema)and dysfunction of small airway.10.Epidemilogical analyses of NHANES(Scannapico et.al.1998, Scannapico and HO 2001) and data from Vetrans Administration Dental Longitudnal Study(VADLS)(HAYES et.al 1998) was the first to suggest possible link between periodontitis and COPD.11.The likehood of COPD is directly proportional to severity of attachment loss of teeth.Loss of attached teeth is also associated with diminishing lung function.1.Acording to Travis and others , pulmonary emphysema and periodontal disease share a similar mechanism of tissue destruction. 12

Flowchart Showing Similar Mechanism Of Tissue Destruction In Pulmonary Emphysema And Periodintal Disease.1.
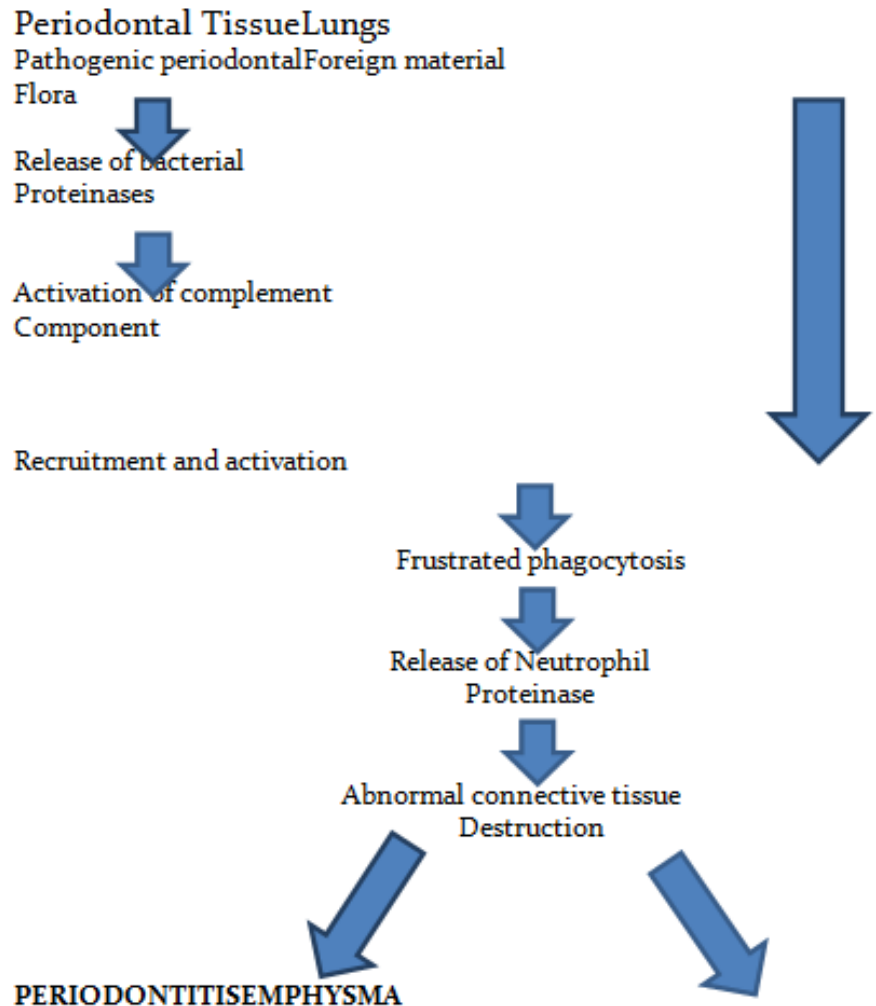

Association between Pulmonary Infction and Oral Disease

Over these years,many studies had been conducted to prove the association between pulmonary infection and oral disease.In this literature review, 6 main studies had been highlighted to prove the association between these 2 groups.

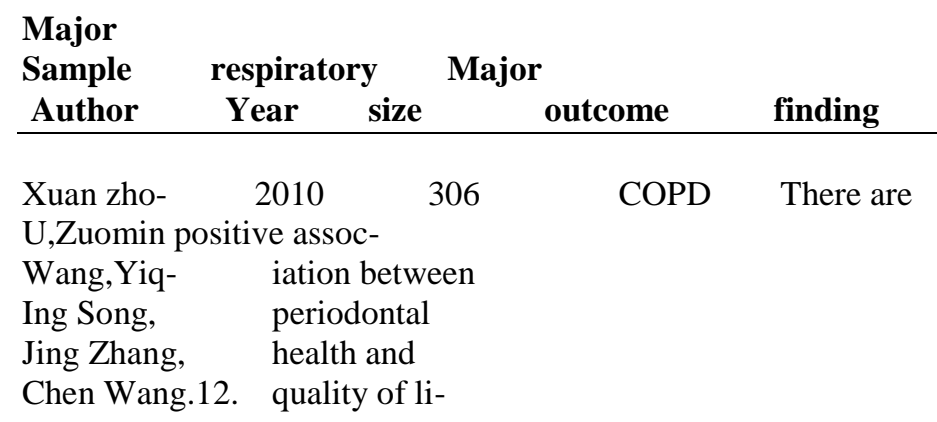

Fe in COPD pa- 


\begin{tabular}{l}
\multicolumn{2}{c}{ tients } \\
$\begin{array}{l}\text { Vikasdeo, } \quad 2013 \quad 150 \\
\text { Manohar L }\end{array}$ \\
$\begin{array}{l}\text { Bhongade, nicalattachme- } \\
\text { Salman Ansari, nt loss the grea- }\end{array}$ \\
Ramesh S cha- ter the associat- \\
Van.4. ion with COPD
\end{tabular}

\begin{tabular}{lccc}
\hline I.Leuckfeld, & $2007 \quad 180$ & COPD & Marginal bone \\
M.V Obrego- & loss is associa- & & \\
n-Whittle,M. & ted with a very & \\
B.Lund,O.Gei- & severe COPD & \\
ran,O.Bjortuft, & & \\
I.Olsen.13. & &
\end{tabular}

S.Yaghobee, $2007 \quad 100 \quad$ Asthma $\quad$ The reports

M.Paknejad, advocate relat-

A.Khorsand.14. ionshipbetwe-

en respiratory

disease and per-

iodontal health

status

Nikhil Shar- $2011 \quad 100$
maH.Shamsu- $\quad$ ia, acutelation between

ratory disease

\begin{tabular}{llcc}
$\begin{array}{l}\text { Magaret S } \\
\text { Tarpenning, }\end{array}$ & $2001 \quad$ 358 & & $\begin{array}{c}\text { Aspira- } \\
\text { tionpneuntal,cariogenic }\end{array}$ \\
$\begin{array}{l}\text { George W tay- } \\
\text { Lor,Dennis C- }\end{array}$ & \multicolumn{1}{c}{ monia } & bacteria and & periodontal \\
Onnie Kinder, & pathogen as & & \\
Liza Doming- & $\begin{array}{l}\text { an important } \\
\text { risk factor for }\end{array}$ & & \\
Uez,Walter J. & aspiration & Pneumonia . & \\
Loesch.16. & &
\end{tabular}

\section{Conclusion}

In conclusion ,of this review,poor periodontal health due to smoking,poor oral hygine,etc. is associated with increased severity of respiratory disease .This is association is seen especially in patients with severely compromised health in elderly patient and in patient with chronic pulmonary disease.Nevertheless, a causal association has not been proven and more studies,in particular intervention studies are needed.

\section{Reference}

[1] Oral Health and Respiratory Infection Philippe Mojon, DMD, PhD •

[2] Russell SL ,BoylanRJ,KaslickRS,ScannpiecoFA,Katz RV Respiratory pathogen colonization of the dental plaque of institutionalized Elders.Spec care dentist 1998;19:128-34

[3] ScannpiecoFA,MylotteeJM.relationship between periodontal disease and bacterial pneumonia.J.periodontal 1996;67:1114-22

[4] Periodontitis as a potential risk factor chronic obstructive pulmonary disease :A retrospective study.VikasDeo,ManoharBhongade,SalmanAnsari,Ramesh S chavan

[5] Savage, Amir; Eaton, Kenneth A.; Moles, David R.; Needleman, Ian (2009). "A systematic review of definitions of periodontitis and methods that have been used to identify this disease". Journal of Clinical Periodontology 36 (6): 458-467. doi:10.1111/j.1600051X.2009.01408.x. PMID 19508246

[6] Page RC ,Beck JD ,Risk assessment for periodontal disease .Int dent j 1997;47:61-87

[7] Loe H, Theilade,E.JensenSB,experimental gingivitis in men.J Periodontal 19 65:36:177

[8] California a book of approved Civil Jury instruction (Baji) Baji no 3.7.6

[9] Association between periodontal disease and risk for nosocomial bacterial pneumonia and COPD .A systemic review.FrankA.Scannapieco, Renee B Bush and Susanna Rj. 
[10] Vestbo, Jorgen (2013). Global Strategy for the Diagnosis, Management, and Prevention of Chronic Obstructive Pulmonary Disease.Global Initiative for Chronic Obstructive Lung Disease. p. Chapter 1.

[11] Periodontal systemic associations: review of the evidence Linden GJ, Lyons A, Scannapieco FA. Periodontal systemic associations: review of the evidence.

[12] Periodontal health and quality of life in patients with chronic obstructivepulmonary disease. Xuan Zhoua,Zuomin Wang a,d, Yiqing Song $\mathrm{b}$,Jing Zhang a ,Chen Wang c,

[13] Severe chronic obstructive pulmonary disease: Association with marginal bone loss in periodontitis Leuckfelda, M.V. ObregonWhittlea,M.B. Lundb,O. Geiranc, Ø. Bjørtuftb,I. Olsena

[14] Association between Asthma and Periodontal Disease S. Yaghobee, M. Paknejad, A. Khorsand

[15] An association between respiratory disease in hospitalized patients and periodontal disease-a cross sectional study.Nikhil Sharma ,H.Shamssudin

[16] .Aspiration Pneumonia: Dental and Oral Risk Factors in an Older Veteran Population

[17] Terpenning, Margaret S.; Taylor, George W.; Lopatin, Dennis E.; Kerr, Connie Kinder; Dominguez, B. Liza; Loesche, Walter J 